\title{
is

\section{Utilização de Macroinvertebrados Bentônicos de Nascentes do Meio Urbano Impactado como Instrumento de Educação Ambiental em uma Escola Pública de Ribeirão das Neves - MG}

\author{
Márcia Aparecida Silva'; Mylla Vaz ${ }^{2}$; Graziele Wolff de Almeida Carvalho ${ }^{3}$
}

\begin{abstract}
RESUMO
Os recursos hídricos são prioritários para o desenvolvimento de praticamente todas as atividades humanas e para a sustentação dos ecossistemas. A preocupação com a qualidade da água movimenta todos os setores da sociedade atualmente, seja pela escassez de água potável em inúmeras regiões, pela precaução no uso deste bem precioso ou ainda pela possibilidade de veiculação hídrica de doenças. A utilização da educação ambiental formal possibilita a continuidade em projetos que devem ser constantemente desenvolvidos nas escolas. Usar os macroinvertebrados bentônicos em atividades de educação ambiental é um instrumento abordado neste trabalho e tem como objetivo demonstrar ambientes preservados e impactados pelo processo de urbanização, respectivamente, na nascente do Rio São Francisco e na cidade de Ribeirão das Neves - MG. Foram realizadas atividades de visita orientada em uma nascente, para enfatizar o pertencimento à uma microbacia hidrográfica, a observação de macroinvertebrados bentônicos durante aulas práticas e a percepção da biodiversidade de seres em ambientes preservados e naqueles com intensa atividade antrópica. Houve a ênfase na utilização da matemática em atividades relacionadas ao dimensionamento da biodiversidade de macroinvertebrados bentônicos. Como resultado do desenvolvimento deste projeto, destaca-se o interesse dos alunos pelo tema, o aprendizado sobre a diversidade aquática e a necessidade de preservação das nascentes e cursos d'água das reservas naturais e nas cidades.
\end{abstract}

Palavras-Chave: Educação Ambiental; Macroinvertebrados Aquáticos; Bacia Hidrográfica.

\footnotetext{
${ }^{1}$ Mestre (Sustentabilidade e Tecnologia Ambiental, IFMG, Brasil). Docente Ensino Médio e Fundamental (EEPAN, Brasil).marciabrasilmg@gmail.com

${ }_{2}$ Graduanda (Medicina, UFOP, Brasil).mylla98@gmail.com

${ }^{3}$ Doutora (Ecologia aplicada), UFV, Brasil). Docente mestrado (IFMG, Brasil). graziele.wolff@hotmail.com
} 


\section{INTRODUÇÃO}

Neste momento a Educação Ambiental é uma das possíveis ferramentas de capacitação e sensibilização da população em geral sobre os problemas ambientais. Com ela busca-se desenvolver técnicas e métodos que facilitem o processo de tomadas de consciência sobre a gravidade dos problemas ambientais e a necessidade urgente de nos debruçarmos seriamente sobre eles.

Para Gonçalves, a escola parece ser o locus privilegiado, daí a proliferação de políticas públicas de inclusão, por exemplo, que favorecem o alargamento das funções da escola, enfatiza ainda que, as escolas têm inserido na pauta do dia a temática ambiental e sua tão sonhada sustentabilidade Gonçalves ${ }^{4}$.

Tornar a escola um espaço educador sustentável contribuirá com a melhoria da relação de aprendizagem Brasil ${ }^{5}$, neste sentido a intervenção junto aos educandos propricia uma percepção das transformações do espaço geográfico suas possíveis consequencias torna a educação ambiental imprescindível para a recuperação e preservação de uma qualidade natural compatível com a vida.

Segundo França $^{6}$, projetos de educação ambiental devem caminhar juntamente com projetos de pesquisa, pois estão intimamente ligados. Abordar conceitos curriculares e ações efetivas cria um ambiente propício ao desenvolvimento de uma consciência que relaciona o meio ambiente com práticas cotidianas.

Neste sentido, a autora, que é professora de ciências e biologia, da Escola Estadual Pedro de Alcântara Nogueira (EEPAN), elabora constantes atividades relacionadas ao tema de meio ambiente, saúde, qualidade de vida, tecnologias sustentáveis, para executar ações de educação ambiental formal e integrar a

\footnotetext{
${ }^{4}$ A. do C. G. Gonçalves; C. M. S. Dias; M. R. A. Mota. Alargamento das funções da escola: educação ambiental e sustentabilidade. ETD - Educação Temática Digital, Campinas, SP, v. 16, n. 3, p.551-569, set./dez. 2014. ISSN 16762592. Disponível em: <http://www.fe.unicamp.br/revistas/ged/etd/article/view/6680>. Acesso em: 11/06/2016.

${ }^{5}$ BRASIL. Ministério da Educação. SECADI. Formando com-vida, comissão de meio ambiente e qualidade de vida na escola: construindo Agenda 21 na escola. 3. ed. rev. e ampl. Brasília: MEC, Coordenação-Geral de Educação Ambiental, 2012.

${ }^{6}$ J. S. França; J. S. Xavier, M. Callisto. Desenvolvimento de atividades lúdicas com os macroinvertebrados bentônicos bioindicadores de qualidade de água. Mostra Nacional de Iniciação Científica e Tecnológica Interdisciplinar - II MICTI Camborí́(SC), 17, 18 e 19 de outubro de 2007 / Colégio Agrícola de Camboriú-UFSC. 2007.
} 
comunidade local a atitudes ecologicamente corretas. O projeto ora apresentado é inédito, entretanto, é uma ação contínua de observação de dados acumulados e releitura destes frente aos novos grupos discentes que são levados a ter contato com o tema geral: meio ambiente e qualidade de vida na cidade de Ribeirão das Neves MG. Realizar atividades práticas, interessantes, dinâmicas e inovadoras para estudos teóricos abordando a temática ambiental, consequências da urbanização, medidas para recuperação ambiental, controle de zoonoses, descrição do saneamento bem como a abordagem do desenvolvimento agroindustrial no âmbito municipal são objetivos específicos deste projeto.

A utilização de macroinvertebrados bentônicos para educação ambiental tem sido empregada por suas características facilitadoras: possibilita a comparação entre ambientes preservados e os impactados por ações antrópicas; são de fácil visualização; podem ser coletados, fixados e usados por muito tempo; podem ser transportados em recipientes de pequeno porte; uma única coleta em determinados pontos amostrais fornece dados que podem ser relacionados à outras disciplinas tais como geografia, matemática e química.

O desenvolvimento deste projeto introduziu ações orientadas pelo Programa Nacional de Educação Ambiental (ProNEA); incentivou a capacidade de reflexão e a criatividade dos alunos voltadas para o pertencimento no eixo de bacia hidrográfica o que reforça este como modelo de gestão sóciambiental, despertou o interesse pela ciência e tecnologia aplicadas ao conceito de saúde ambiental, além de desenvolver atividade multidisciplinar ao usar os cálculos matemáticos em relação à mensuração de biodiverdidade dos macroinvertebrados bentônicos.

\section{METODOLOGIA / MÉTODOS}

Para a realização do trabalho, os alunos de duas turmas dos segundos anos do ensino médio: verde mar e verde oliva foram agrupados em quatro a seis participantes. Os alunos fizeram visitas "in loco" à uma nascente localizada no Parque Ecológico, conforme localização na figura 1. Durante a visita, os alunos realizaram 
também a coleta de folhas vegetais para a montagem de uma exsicata, outra atividade desenvolvida nas aulas de biologia.

Figura 1 - Localização da nascente e pontos de coleta.

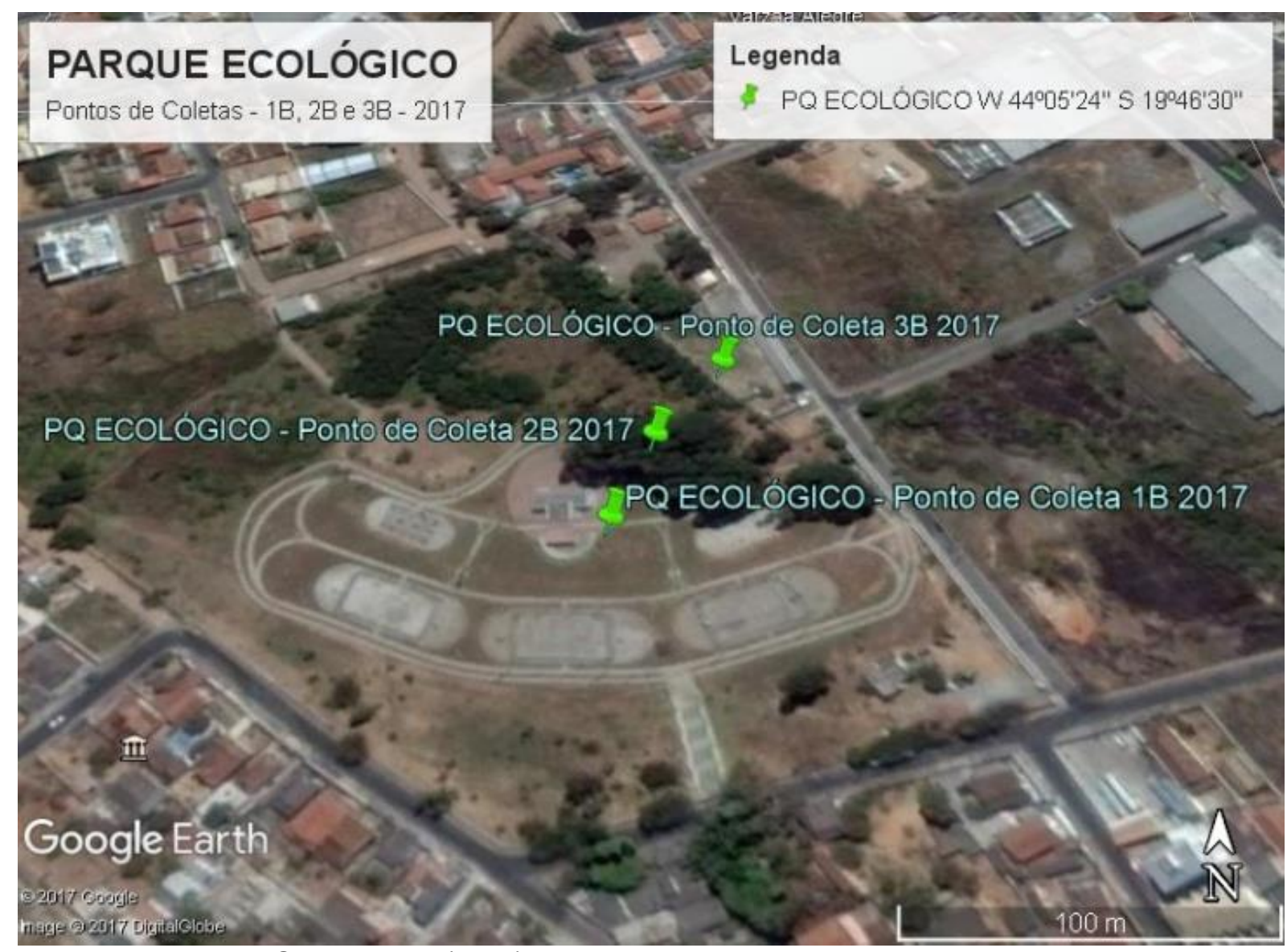

Fonte: Adaptado de Google Earth (2017)

As autoras realizaram a coleta em três pontos, conforme figura 1 e a descrição da situação ambiental da área no entorno da nascente, informados no quadro 1, em avaliação ambiental da nascente e curso d'água a jusante chegou-se ao resultado de um estado de preservação ruim, conforme Gomes et $\mathrm{al}^{7}$.

Quadro 1 - Descrição da avaliação ambiental da nascente e curso d'água

\begin{tabular}{|l|l|l|l|}
\hline & \multicolumn{1}{|c|}{$\begin{array}{c}\text { PONTO 1B } \\
\text { NACENTE } \\
\mathbf{0 - 5 0 m}\end{array}$} & $\begin{array}{c}\text { PONTO 2B } \\
\text { CURSO D'ÁGUA } \\
\mathbf{5 1 - 1 0 0 m}\end{array}$ & $\begin{array}{c}\text { PONTO 3B CURSO } \\
\text { D'ÁGUA } \\
\mathbf{1 0 1 - 1 5 0 m}\end{array}$ \\
\hline 01. Cor da agua & (3) transparente & (3) transparente & (3) transparente \\
\hline 02. Odor & (3) sem cheiro & (3) sem cheiro & (3) sem cheiro \\
\hline 03. Lixo ao redor & (2) pouco & (2) pouco & (2) pouco \\
\hline 04. Materiais flutuantes & (2) pouco & (2) pouco & (2) pouco \\
\hline
\end{tabular}

\footnotetext{
${ }^{7}$ P. M. Gomes; C. Melo; V. S. Vale. Avaliação dos impactos ambientais em nascentes na cidade de Uberlândia-MG:
} análise macroscópica. Sociedade \& Natureza, Uberlândia, 17 (32). p.103-120. Jun. 2005. 


\begin{tabular}{|c|c|c|c|}
\hline 05. Espumas & (3) ausente & (2) pouca & (2) pouca \\
\hline 06. Óleos & (3) ausente & (3) ausente & (3) ausente \\
\hline 07. Esgoto & (2) fluxo superficial & (2) fluxo superficial & (2) fluxo superficial \\
\hline 08. Vegetação & (1) alta degradação & (1) alta degradação & (1) alta degradação \\
\hline 09. Uso por animais & (3) não detectado & (3) não detectado & (3) não detectado \\
\hline 10. Uso por humanos & (3) não detectado & (3) não detectado & (3) não detectado \\
\hline 11. Proteção local & (1) sem proteção & (1) sem proteção & (1) sem proteção \\
\hline 12. Proximidade com edificação & (1) menor $50 \mathrm{~m}$ & (2) $50-100 \mathrm{~m}$ & (2) $50-100 m$ \\
\hline 13. Tipo de inserção & $\begin{array}{ll}\text { (3) } & \text { parque } \\
\text { ecológico } & \end{array}$ & $\begin{array}{ll}\text { (3) } & \text { parque } \\
\text { ecológico } & \end{array}$ & (3) parque ecológico \\
\hline TOTAL & 30 pontos & 30 pontos & 30 pontos \\
\hline AVALIAÇÃO & Ruim & Ruim & Ruim \\
\hline
\end{tabular}

Fonte: Gomes et al ${ }^{8}$, modificado pelos autores, 2017.

As atividades realizadas são apresentadas no quadro 2.

Quadro 2 - Descrição das atividades realizadas pelos grupos de alunos

\begin{tabular}{|c|c|}
\hline ATIVIDADES & DESCRIÇÃO \\
\hline Apresentação do tema & $\begin{array}{l}\text { Abordagem teórica sobre ítens relacionados ao } \\
\text { tema }\end{array}$ \\
\hline Formação dos grupos e orientações gerais & Preparo e organização para saída a campo \\
\hline Saída a campo & Visita orientada ao Parque ecológico \\
\hline Abordagem ecológica & $\begin{array}{l}\text { Descrição da implantação do parque, } \\
\text { características gerais e específicas sobre a } \\
\text { nascente e curso d água }\end{array}$ \\
\hline $\begin{array}{l}\text { Coleta de macroinvertebrados nos } 3 \text { pontos no } \\
\text { Parque ecológico }\end{array}$ & Realizado pela professor/orientadora \\
\hline Aulas práticas & $\begin{array}{l}\text { Identificação de macroinvertebrados e análises } \\
\text { das amostras em arquivo }\end{array}$ \\
\hline Aulas teóricas & $\begin{array}{l}\text { Realização dos cálculos e análises dos mesmos } \\
\text { frente à biodiversidade }\end{array}$ \\
\hline
\end{tabular}

Fonte: Autores, 2017

Para coleta de macroinvertebrados bentônicos foi utilizada uma rede de mão de arrasto com $25 \mathrm{~cm}$ de largura e de malha $0,5 \mathrm{~mm}$, posicionado contra a correnteza na área de amostragem no leito do curso d'água. O material foi transferido para sacos plásticos com capacidade de até cinco litros, adicionado formaldeído na concentração de 37\%. Cada saco foi identificado, transportado para ser triado por catação em bandejas, com aumento de 10x e 40x, identificados os grupos taxionômicos em ordens e famílias. Os exemplares de macroinvertebrados bentônicos, foram acondicionados em frascos, de capacidade para $300 \mathrm{ml}$, identificados, fixados com álcool 70\% e depositados em armários à temperatura ambiente, para demonstração nas aulas práticas posteriores.

\footnotetext{
${ }^{8}$ P. M. Gomes; C. Melo; V. S. Vale. Avaliação Microbiológica e Físico química em Nascentes na Cidade de Uberlândia MG. In: VII Congresso de Ecologia do Brasil, 2005, Caxambu. Anais do..., 2005.
} 
Como atividades de aulas práticas os alunos foram levados a reconhecerem os macroinvertebrados bentônicos identificados pela autora dos 3 pontos da nascente no Parque Ecológico. Realizaram também a visualização de macroinvertebrados bentônicos em cinco famílias coletadas na nascente do Rio São Francisco e observaram as famílias identificadas em três nascentes do município, ambas coletas, identificadas no ano de 2016 e mantidas em conservação.

\section{RESULTADOS E DisCUSSÃo}

A realização deste projeto possibilitou uma abordagem sobre os conceitos de pertencimento, de bacia hidrográfica e as conseqüências das ações antrópicas desenvolvidas ao longo das sub e microbacias integrantes da calha do Rio São Francisco.

O Município de Ribeirão das Neves foi fundado em 12 de dezembro de 1953, basicamente com uma economia de produção e comercialização de hortaliças. Após 1970, passou a apresentar um crescimento demográfico acentuado promovido pela expansão imobiliária da região da capital mineira. Com a implantação de mais de quatro unidades prisionais, e sem oferecer postos de serviços para a mão de obra local, Neves, passou a ser considerada uma cidade-dormitório. A partir de 1990, o município inicia um processo de crescimento sócio-econômico com a intensificação do comércio e da indústria local, segundo IBGE .

As características gerais do município encontram-se dispostas no quadro 3.

Quadro 3 - Caracterização Geral de Ribeirão das Neves

\begin{tabular}{|l|l|l|}
\hline \multicolumn{1}{|c|}{ ÍTEM } & \multicolumn{1}{|c|}{ DESCRIÇÃO } & FONTE CONSULTADA/ANO \\
\hline Localização & Região Metropolitana de Belo Horizonte/MG & IBGE, 2015 \\
\hline Área & $155,541 \mathrm{Km}^{2}$, & IBGE, 2015 \\
\hline População & 296.317 & IBGE, 2010 \\
\hline IDH & 0,684 & IBGE, 2012 \\
\hline
\end{tabular}

\footnotetext{
9 IBGE - Instituto Brasileiro de Geografia e Estatística, 2010. Acesso em 24 de abril de 2016. Disponível em https://ww2.ibge.gov.br/home/estatistica/perfilmunic/2010/default.shtm

10 IBGE - Instituto Brasileiro de Geografia e Estatística, 2015. Acesso em 24 de abril de 2016. Disponível em https://ww2.ibge.gov.br/home/estatistica/perfilmunicipal/2015/shtm

11 Ibid.

12 IBGE - Instituto Brasileiro de Geografia e Estatística, 2010
} 
Márcia Aparecida Silva; Mylla Vaz; Graziele Wolff de Almeida Carvalho

\begin{tabular}{|c|c|c|}
\hline $\begin{array}{l}\text { PIB - } \quad \text { Valor } \\
\text { adicionado bruto de } \\
\text { serviços }\end{array}$ & 2.000 .166 (mil reais) & IBGE, $2008^{14}$ \\
\hline Coleta seletiva & $\begin{array}{l}\text { Alguns bairros da área urbana da sede } \\
\text { municipal }\end{array}$ & PNSB, $2008^{15}$ \\
\hline Catadores & $\begin{array}{l}\text { Existem catadores no perímetro urbano } \\
\text { municipal }\end{array}$ & PNSB, $2008^{16}$ \\
\hline $\begin{array}{l}\text { Manejo de resíduos } \\
\text { sólidos }\end{array}$ & Prefeitura e outras executam & PNSB, $2008^{1 /}$ \\
\hline Vegetação & $\begin{array}{l}\text { Região de transição entre Cerrado e Mata } \\
\text { Atlântica }\end{array}$ & IBGE, $2010^{18}$ \\
\hline Clima & CWB - Clima Tropical de Altitude & IBGE, $2010^{19}$ \\
\hline Unidade de relevo & Depressão Sanfranciscana & IBGE, $2015^{2 U}$ \\
\hline Bacia Hidrográfica & $\begin{array}{l}\text { Rio São Francisco/Sub-bacia do Ribeirão da } \\
\text { Mata }\end{array}$ & IBGE, $2015^{21}$ \\
\hline
\end{tabular}

Fonte: Autores, 2017

Os alunos conheceram a utilização dos macroinvertebrados bentônicos como bioindicadores de qualidade de água; avaliaram o do estado de degradação ambiental de nascentes e córregos da cidade onde vivem, a necessidade de recuperação dos recursos hídricos no meio urbanizado e a preservação de reservas naturais da biodiversidade como o Parque Nacional da Serra da Canastra.

Na figura 2 encontra-se o registro fotográfico da visita orientada ao Parque Ecológico, momento onde os alunos foram estimulados a observar a geografia do terreno onde o parque situa-se, avaliar o relevo e as ações antropogênicas que alteraram o espaço natural.

Figura 2 - Participação dos alunos nas atividades de campo

\footnotetext{
${ }^{13}$ IBGE - Instituto Brasileiro de Geografia e Estatística, 2012. Acesso em 24 de abril de 2016. Disponível em https://ww2.ibge.gov.br/home/estatistica/perfilmunic/2012/d.shtm

14 IBGE - Instituto Brasileiro de Geografia e Estatística, 2008. Acesso em 26 de abril de 2016. Disponível em https://ww2.ibge.gov.br/home/estatistica/perfilmunic/2008/default.shtm

15 lbid.

16 Ibid.

17 lbid.

${ }^{18}$ IBGE - Instituto Brasileiro de Geografia e Estatística, 2010

${ }^{19}$ lbid.

20 IBGE - Instituto Brasileiro de Geografia e Estatística, 2015

${ }^{21}$ lbid.
} 


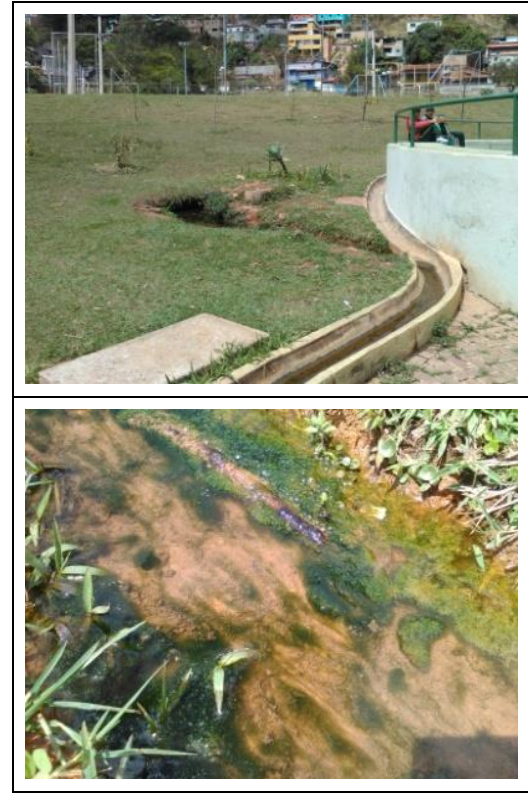

A. Ponto 1B - Nascente

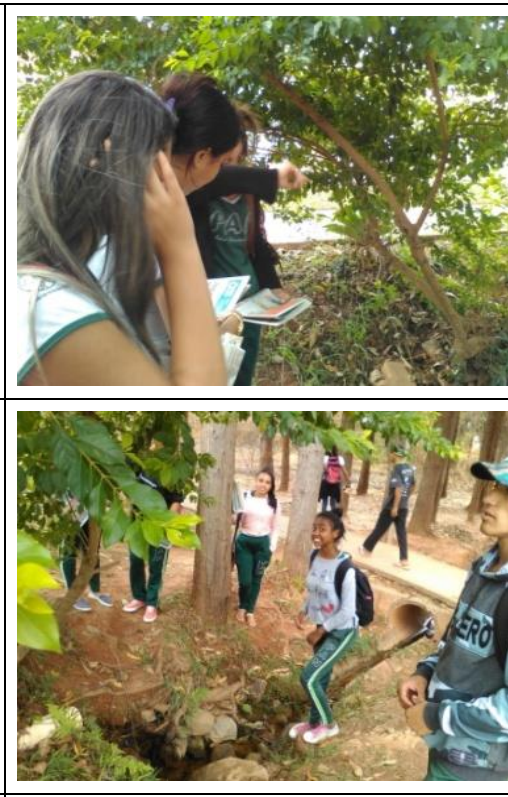

B. Ponto 2B - Curso d'água

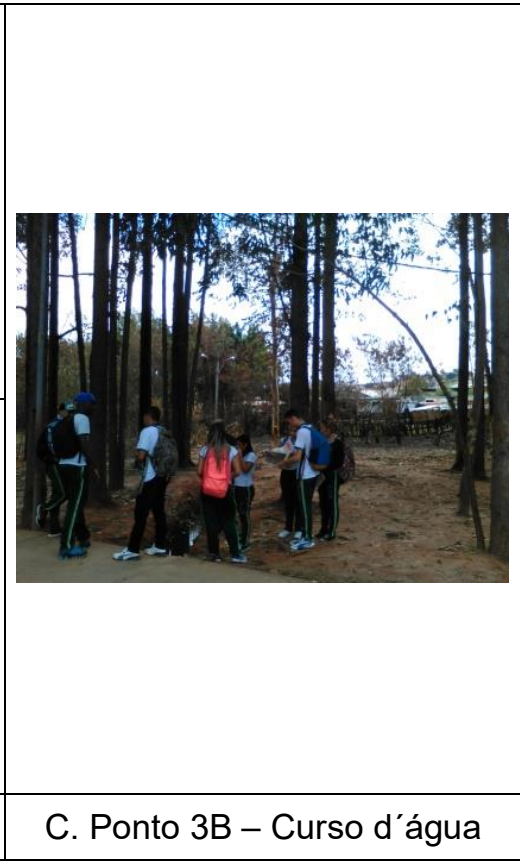

Fonte: Autores, 2017

Na figura 3 é apresentado o registro fotográfico de alguns dos exemplares coletados nas três fases do projeto.

Figura 3 - Registro dos Exemplares Coletados em Cada Ponto Visitado

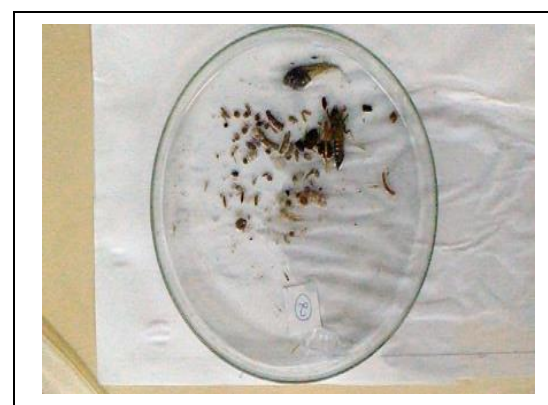

Exemplares da amostra 2 da nascente histórica do Rio São Francisco, 2016

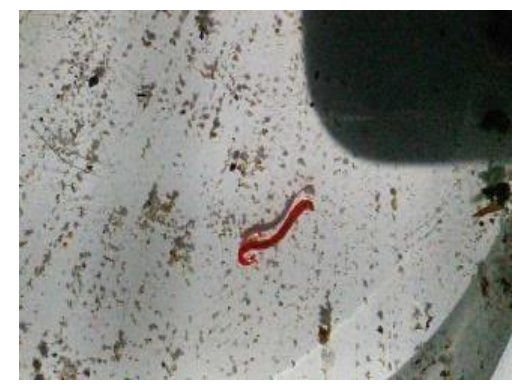

Exemplares da amostra $1 \mathrm{da}$ nascente do Córrego Voz da Natureza, 2016

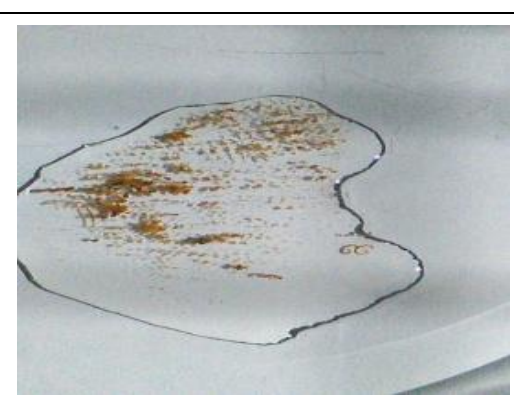

Exemplares da amostra $1 \mathrm{da}$ nascente do Parque Ecológico, 2017

Fonte: Arquivo dos Autores, 2016, 2017

As famílias identificadas nas amostras do Parque Ecológico encontram-se dispostas no quadro 4, nesta tabela encontram-se descritas também as famílias identificadas no ano de 2016 nas nascentes do Rio São Francisco e Córrego Voz da Natureza.

Quadro 4 - Identificação das famílias de macroinvertebrados bentônicos

\begin{tabular}{|c|c|c|c|c|c|}
\hline & $\begin{array}{c}\text { NASCENTE RIO SÃO } \\
\text { FRANCISCO }\end{array}$ & $\begin{array}{c}\text { NASCENTE } \\
\text { CÓRREGO }\end{array}$ & $\begin{array}{c}\text { NASCENTE } \\
\text { PARQUE }\end{array}$ & $\begin{array}{c}\text { NASCENTE } \\
\text { PARQUE }\end{array}$ & $\begin{array}{c}\text { NASCENTE } \\
\text { PARQUE }\end{array}$ \\
\hline
\end{tabular}




\begin{tabular}{|l|l|c|c|c|c|}
\hline & \multicolumn{1}{|c|}{ PONTO 1 } & $\begin{array}{c}\text { VOZ DA } \\
\text { NATUREZA }\end{array}$ & $\begin{array}{c}\text { ECOLÓGICO } \\
\text { PONTO 1B }\end{array}$ & $\begin{array}{c}\text { ECOLÓGICO } \\
\text { PONTO 2B }\end{array}$ & $\begin{array}{c}\text { ECOLÓGICO } \\
\text { PONTO 2B }\end{array}$ \\
\hline FAMÍLIAS & $\begin{array}{l}\text { Psepheenidae } \\
\text { Helicopsychidae } \\
\text { Hydroptiidae } \\
\text { Oligoneuridae } \\
\text { Odontoceridae } \\
\text { Gerridae } \\
\text { Aeshnidae } \\
\text { Chironomidae }\end{array}$ & Chironomídae & $\begin{array}{l}\text { Odontoceridae } \\
\text { Gerridae }\end{array}$ & Odontoceridae & Chironomidae \\
\hline
\end{tabular}

Fonte: Arquivo dos Autores, 2016, 2017

Em atividade multidisciplinar para relacionar dados ambientais com a matemática, os alunos avaliaram as operações e resultados obtidos nos cálculos apontados por Shannon-Wiener (H') e Pielou (J'), para diversidade e equabilidade, usados para mensurar a diversidade de macroinvertebrados bentônicos em ambientes aquáticos.

Segundo INAG ${ }^{22}$, o índice de Shannon (também chamado de índice ShannonWeaver ou de índice do Shannon-Wiener) é um dos diversos índices da diversidade usados para medir a diversidade em dados categóricos, pode ser encontrado com a equação:

$$
H^{\prime}=\sum_{i=1}^{S}\left(p_{i}\right)\left(\operatorname{In} p_{i}\right)
$$

Em que: $\left(\operatorname{In} p_{i}\right)$ - número de indivíduos em cada grupo; $S$ - número de espécies (riqueza); $\left(p_{i}\right)$ - abundância relativa $n_{i} / N ; N$ - número total de todos os indivíduos.

Segundo $\mathrm{INAG}^{23}$, o índice de Pielou $\left(J^{\prime}\right)$, aponta a equitabilidade das espécies em estudo. Pode ser encontrado com o uso da equação:

$$
J^{\prime}=\frac{H^{\prime}}{\operatorname{Hmax}}
$$

Em que: $H^{\prime}$ - observado; Hmax - diversidade máxima possível, número total de espécies.

\footnotetext{
${ }^{22}$ I. P. Inag. Manual para a avaliação biológica da qualidade da água em sistemas fluviais segundo a Directiva Quadro da Água Protocolo de amostragem e análise para os macroinvertebrados bentônicos. Ministério do Ambiente, Ordenamento do Território e do Desenvolvimento Regional. Instituto da Água. IP. Lisboa. 2008.

${ }^{23}$ lbid
} 
A análise das equações foi ilustrativa para que os alunos observassem a importância do uso dos cálculos matemáticos em monitoramento ecológico de biodiversidade, fazem-se necessários estudos pormenorizados para aprofundamento dos índices apontados. Os dados obtidos com os cálculos encontram-se relacionados na tabela 1 e aponta para maior diversidade no ponto de coleta $1 \mathrm{~B}$, nascente propriamente dita, local onde foi visualizado um grupo de peixes em movimento e presença de vegetais aquáticos, conforme descrito na tabela 1.

Tabela 1 - Resultados de cálculos por Shannon-Winer $\left(\boldsymbol{H}^{\prime}\right)$ e Pielou $\left(\boldsymbol{J}^{\prime}\right)$ para as amostras coletadas nos pontos na nascente do Parque Ecológico

\begin{tabular}{|l|c|c|c|c|} 
& ESPÉCIES & FAMíLIAS & $\boldsymbol{H}^{\prime}$ & $\boldsymbol{J}^{\prime}$ \\
\hline Ponto 1B & 34 & 2 & 0,6210 & 0,4981 \\
\hline Ponto 2B & 23 & 1 & 0,3183 & 0,4592 \\
\hline Ponto 3B & 22 & 1 & 0,2812 & 0,4057 \\
\hline Fonte: Autores, 2017 & & &
\end{tabular}

Nas aulas práticas em laboratório os alunos tiveram acesso à visualização de macroinvertebrados bentônicos bioindicadores de qualidade de água provenientes de trabalho concluído pelos alunos do mestrado do Instituto Técnico Federal de Minas Gerais, Campus Bambuí, em atividade de campo realizada na nascente histórica do Rio São Francisco, na Serra da Canastra, sob a orientação da professora Graziele Wolff.

Os alunos foram estimulados a comparar a biodiversidade de seres apontados nas coletas da nascente do Rio São Francisco, bem como analisar a baixa biodiversidade constatada nas coletas realizadas nos córregos na cidade de Ribeirão das Neves, com esta abordagem os alunos perceberam a influência dos fatores antrópicos, suas consequências para o meio ambiente, a saúde e a qualidade de vida em geral, no nível local, regional, nacional e planetário.

Um aspecto relevante foi a realização dos cálculos matemáticos para avaliar a diversidade de espécies, relacioná-la com a preservação ou degradação ambiental. Este foi um marco no desenvolvimento deste projeto pois, evidenciou dados, trouxe para a realidade dos alunos o uso da matemática em questões cotidianas através da educação ambiental formal, em espaços freqüentados constantemente por eles, desmistificando, neste sentido, o uso de equações, realização de cálculos para 
obtenção de resultados matemáticos, aplicados à situações diversificadas, tais como avaliação ambiental de nascentes em meio urbanizado e em áreas protegidas.

Como atividade final de encerramento anual, os alunos realizaram a montagem das exsicatas, caracterização das folhas vegetais e exposição no ambiente escolar, juntamente com a publicidade dos dados do estudo dos macroinvertebrados bentônicos, o que pode ser observado na figura 4.

Figura 4 - Registro fotográfico de exposição das exsicatas e publicidade do projeto

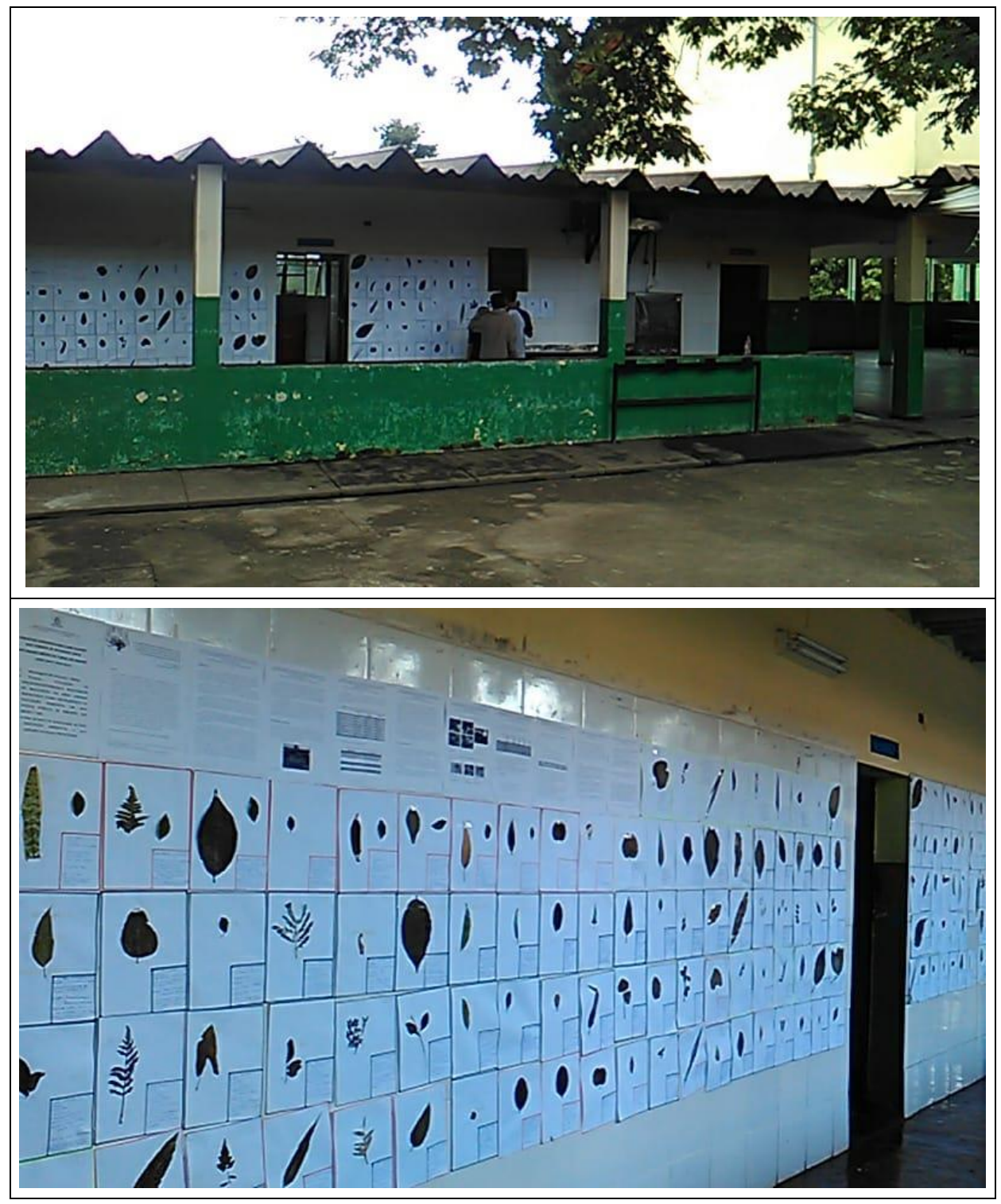

Fonte: Arquivo dos Autores, 2017 


\section{REFERÊNCIAS}

B. Bis and G. Kosmala, "Chave de Identificação para Macroinvertebrados Bentónicos de Água Doce. Departamento de Liminologia e Ecologia de Invertebrados. Instituto de Ecologia e Proteção Ambiental, Universidade de Lódz, Polónia." EC funded Project CONFRESH. 226682-CP-1. GR-COMENIUS-C21 (2005): Disponível em www.nhmc.uoc.gr/confresh

BRASIL. Ministério da Educação. SECADI. Formando com-vida, comissão de meio ambiente e qualidade de vida na escola: construindo Agenda 21 na escola. 3. ed. rev. e ampl. Brasília: MEC, Coordenação-Geral de Educação Ambiental, 2012.

J. S. França, J. S. Xavier and M. Callisto, "Desenvolvimento de atividades lúdicas com os macroinvertebrados bentônicos bioindicadores de qualidade de água" (Apresentado na Mostra Nacional de Iniciação Científica e Tecnológica Interdisciplinar - II MICTI Camboriú, Brasil, 17, 18 e 19 de outubro de 2007 / Colégio Agrícola de CamboriúUFSC. 2007)

P. M. Gomes, C. Melo and V. S. Vale, "Avaliação dos impactos ambientais em nascentes na cidade de Uberlândia-MG:análise macroscópica". Sociedade E Natureza, 17, 32. (Jun. 2005 a): 103-120.

P. M. Gomes, C. Melo and V. S. Vale, "Avaliação Microbiológica e Físico química em Nascentes na Cidade de Uberlândia - MG" (Apresentado no VII Congresso de Ecologia do Brasil, 2005, Caxambu. Anais do..., 2005 b)

A. do C. G. Gonçalves, C. M. S., Dias and M. R. A. Mota, "Alargamento das funções da escola: educação ambiental e sustentabilidade", ETD - Educação Temática Digital, 16, 3 (set./dez. 2014): 551-569. Disponível em: <http://www.fe.unicamp.br/revistas/ ged/etd/article/view/6680>. Acesso em: 11/06/2016.

IBGE - Instituto Brasileiro de Geografia e Estatística. Acesso em 13 abr. 2016. Disponível http://www.cidades.ibge.gov.br/xtras/perfil.php?lang=\&codmun=352044

I. P. Inag, Manual para a avaliação biológica da qualidade da água em sistemas fluviais segundo a Directiva Quadro da Água Protocolo de amostragem e análise para os macroinvertebrados bentônicos (Lisboa: Ministério do Ambiente, Ordenamento do Território e do Desenvolvimento Regional. Instituto da Água. IP, 2008) 


\title{
Utilization of Bentonic Macroinvertebrates of Nascents of the Urban Environment Impacted as Instrument of Environmental Education in a Public School of Ribeirão das Neves - MG
}

\begin{abstract}
Water resources are a priority for the development of practically all human activities and for sustaining ecosystems. Concern about water quality moves all sectors of society today, whether due to the scarcity of drinking water in many regions, the precaution in the use of this precious commodity or the possibility of water supply of diseases. The use of formal environmental education allows for continuity in projects that must be constantly developed in schools. The use of benthic macroinvertebrates in environmental education activities is an instrument approached in this work and aims to demonstrate environments preserved and impacted by the urbanization process, respectively, in the source of the São Francisco River and in the city of Ribeirão das Neves - MG. Orientation-oriented activities were carried out in a spring to emphasize the belonging to a hydrographic basin, the observation of benthic macroinvertebrates during practical classes and the perception of the biodiversity of beings in preserved environments and in those with intense antropic activity. There was an emphasis on the use of mathematics in activities related to the design of benthic macroinvertebrate biodiversity. As a result of the development of this project, we highlight the students' interest in the subject, the learning about aquatic diversity and the need to preserve the springs and water courses of the natural reserves and in the cities.
\end{abstract}

Keywords: Environmental Education; Aquatic Macroinvertebrates; Hydrographic Basin.

Recibido: 17/09/2017

Aprobado: 25/06/2018 